\title{
Negative Appendicectomy Rates and Implication of Preoperative Imaging: A Retrospective Cohort Study
}

\author{
Mohammad Miah*, Daniel Centea, Cindy Cleto, Rabia Yusuf, Najam Husain and Pradeep Thomas \\ University Hospital of Derby and Burton NHS Trust, Queens Hospital Burton, Belvedere Rd, UK \\ *Corresponding author: Mohammad Miah, Specialty Doctor, General Surgery, University hospital of Derby and Burton \\ NHS Trust, Queens Hospital Burton, Belvedere Rd, Burton Upon Trent, DE13 0RB, UK
}

ARTICLE INFO

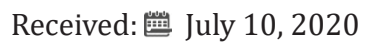

Published: 慧 July 15, 2020

Citation: Mohammad M, Daniel C, Cindy C, Rabia Y, Najam H, Pradeep T. Negative Appendicectomy Rates and Implication of Preoperative Imaging: A Retrospective Cohort Study. Biomed J Sci \& Tech Res 28(5)2020. BJSTR. MS.ID.004722.

\section{ABSTRACT}

Introduction: Recent studies from the United Kingdom showed that Negative Appendicectomy Rate (NAR) ranges from 19\% to 33.9\%. The Royal College of Surgeons in Ireland in 2005 issued a Grade B recommendation that a macroscopically normal appendix may be left in situ. However, counterarguments in favor of removing the normal appendix are that it can hide microscopic appendicitis or other pathology and that removal does not lead to increased morbidity or complications.

Methods: 100 consecutive patients who underwent both open and laparoscopic emergency appendicectomy in our district general hospital from June 2019 till November 2019.

Results: The negative appendicectomy rate was $22 \%$. With pre-operative CT scan, it came down to $11.5 \%$. If all patients undergo pre-operative CT, with a reduction of $10.5 \%$ in negative appendicectomy rate, the overall total cost reduction would be $£ 23,700$. Preoperative consultant review did not reduce NAR rather increased.

Conclusion: Finally, our study revealed that the negative appendicectomy rate could be improved by preoperative imaging. Further studies should focus on a consistent CT protocols to reduce the risk of radiation, especially in young adult and females.

\section{Introduction}

Appendicitis was the cause of 40,588 emergency admissions with 33,193 emergency appendicectomies performed in England from April 2012 to March 2013 [1]. There is presently no standard definition of a negative appendicectomy (NA) as it can refer to a macroscopically or histopathologically normal appendix [2,3]. Recent studies from the United Kingdom show NARs that range from $19 \%$ to $33.9 \%$ [4-9]. Internationally, a NAR of $15.3 \%$ was reported in 261,134 patients from the United States in 2002 [10]. Brockman et al. summarized 11 recent international large studies to generate a combined NAR of $26 \%$ [11]. There is also considerable argument about the management of the normal appendix. The Royal College of Surgeons in Ireland in 2005 issued a Grade B recommendation that a macroscopically normal appendix may be left in situ [12]. This point of view has been strengthened more recently by other authors who argue that removal of a normal appendix increases morbidity and length of stay $[10,13]$. However, counterarguments in favour of removing the normal appendix are that it can hide microscopic appendicitis or other pathology and that removal does not lead to increased morbidity or complications $[5,14,15]$. Surgical practice and opinion are similarly divided. In the UK, a multi-center audit in 2013 showed a wide variation in surgical practice regarding appendicitis and appendicectomy [7]. Internationally, a survey of 364 surgeons from America and Europe showed that 64e73\% backed the removal of a macroscopically normal appendix [16].

\section{Methods and Materials}

Our study aimed to determine our NAR, to identify the effect of pre-operative Alvarado Scoring / Imaging / Consultant review on NAR and the cost reduction strategies by reducing NAR. Data were collected retrospectively. 100 consecutive patients who underwent both open and laparoscopic emergency appendicectomy in our district general hospital from June 2019 till November 2019. Patients under 18 years old were excluded from this study. For our study, 
Negative appendicectomy was defined as a pathologically normal appendix removed from patients suspected with appendicitis.

\section{Results}

100 patients were included in this retrospective study (Figure 1). Average age of patients undergoing appendicectomy 33 years. Male patients were 47 and Female patients were 53. Female to male ratios 53:47. Number of patients not seen by consultants 37 . The negative appendicectomy rate was $22 \%$ (Table 1). With pre-operative CT scan, it came down to $11.5 \%$. One patient had preoperative MRI due to pregnancy (Table 2). Based on the 2018/19 national tariff payment scheme, a CT abdomen and pelvis with contrast and emergency appendicectomy cost 92 and $£ 2370$, respectively. The total cost of patients who underwent appendicectomy without imaging was $£ 2,37,000$. If all patients undergo pre-operative CT, with a reduction of $10.5 \%$ in negative appendicectomy rate, the overall total cost reduction would be $£ 23,700$. Preoperative consultant review did not reduce NAR rather increased. Obviously, most of these patients were the patients who underwent diagnostic laparoscopy and the macroscopically normal appendix was removed after no other cause was found. Even though not all patients had sufficient data to calculate Alvarado score, it was not found significant in reduction of NAR (Table 3 ).

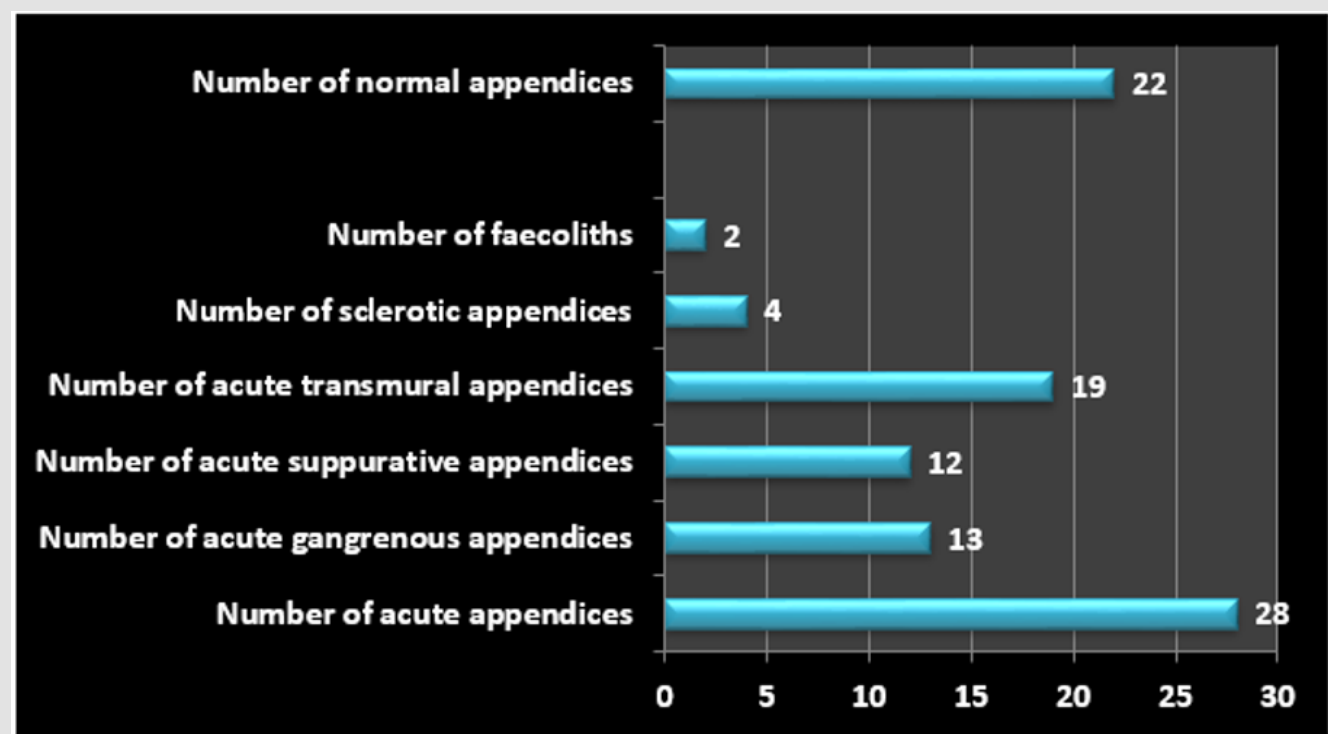

Figure 1: Histopathological findings for all the patients.

Table 1: Effect of preoperative consultant review.

\begin{tabular}{|c|c|c|c|c|}
\hline Preop Consultant review & Acute appendicitis & Normal appendix & Total patient & NAR \\
\hline $\begin{array}{c}\text { Patient reviewed by } \\
\text { consultants }\end{array}$ & 47 & 16 & 63 & $25 \%$ \\
\hline $\begin{array}{c}\text { Patient not reviewed by } \\
\text { consultants }\end{array}$ & 31 & 6 & 37 & $16 \%$ \\
\hline
\end{tabular}

Table 2: Effect of preoperative imaging.

\begin{tabular}{|c|c|c|c|}
\hline Imaging & Acute appendicitis & Normal appendix & NAR \\
\hline CT scan showed Acute appendicitis & 23 & 3 & $11.50 \%$ \\
\hline Ct scan showed normal appendicitis & 1 & 0 & \\
\hline MRI due to Pregnancy & 1 & 0 & \\
\hline
\end{tabular}

Table 3: Significance of Alvarado scoring.

\begin{tabular}{|c|c|c|c|}
\hline Alvarado score & Acute appendicitis & Normal appendix & NAR \\
\hline$>/=7$ & 7 & 2 & $22 \%$ \\
\hline$<7$ & 2 & 1 & $33 \%$ \\
\hline
\end{tabular}




\section{Conclusion}

Finally, our study revealed that the negative appendicectomy rate could be improved by preoperative imaging. This study also showed that implementation of preoperative imaging for suspected appendicitis cases would be cost saving, allowing better distribution of resources. Further studies should focus on a consistent CT protocols to reduce the risk of radiation, especially in young adult and females.

\section{Disclosure, Ethics and Funding}

No conflicts of interest to disclose. This study was registered with relevant department of the hospital. Data were collected retrospectively, and no patients' identifiable numbers were used. No funding was involved.

\section{References}

1. (2013) Health \& Social Care Information Centre, Hospital Episode Statistics, Admitted Patient Care, England 2012e13.

2. U Güller, L Rosella, J McCall, LE Brügger, D Candinas (2011) Negative appendicectomy and perforation rates in patients undergoing laparoscopic surgery for suspected appendicitis. Br J Surg 98(4): 589e595.

3. JG Mariadason, WN Wang, MK Wallack, A Belmonte, H Matari (2012) Negative appendicectomy rate as a quality metric in the management of appendicitis: impact of computed tomography, Alvarado score and the definition of negative appendicectomy. Ann R Coll Surg Engl 94(6): 395e401.

4. F Akbar, M Yousuf, RJ Morgan, A Maw (2010) Changing management of suspected appendicitis in the laparoscopic era. Ann R Coll Surg Engl 92(1): 65-e68.

5. R Marudanayagam, GT Williams, BI Rees (2006) Review of the pathological results of 2660 appendicectomy specimens. J Gastroenterol 41(8): 745-e749.

ISSN: 2574-1241

DOI: 10.26717/BJSTR.2020.28.004722

Mohammad Miah. Biomed J Sci \& Tech Res

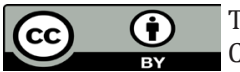

This work is licensed under Creative Commons Attribution 4.0 License

Submission Link: https://biomedres.us/submit-manuscript.php
6. PG Vaughan Shaw, JR Rees, E Bell, M Hamdan, T Platt (2011) Normal inflammatory markers in appendicitis: evidence from two independent cohort studies. JRSM Short Rep 2(5): 43.

7. (2013) National Surgical Research Collaborative, Multicentre observational study of performance variation in provision and outcome of emergency appendicectomy. Br J Surg 100(9): 1240-e1252.

8. SF Brockman, S Scott, GD Guest, DA Stupart, S Ryan (2013) Does an Acute Surgical Model increase the rate of negative appendicectomy or perforated appendicitis? ANZ J Surg 83(10): 744-e747.

9. IG Panagiotopoulou, D Parashar, R Lin, S Antonowicz, D Wells, et al. (2013) The diagnostic value of white cell count, C-reactive protein and bilirubin in acute appendicitis and its complications. Ann R Coll Surg Engl 95(3): 215-e221.

10. DR Flum, T Koepsell (2002) The clinical and economic correlates of misdiagnosed appendicitis: nationwide analysis. Arch Surg 137(7): 799e804.

11. S Charfi, A Sellami, A Affes, K Yaïch, R Mzali (2014) Histopathological findings in appendectomy specimens: a study of 24,697 cases. Int J Colorectal Dis 29(8): 1009-e1012.

12. HP Redmond (2005) The Royal College of Surgeons of Ireland, Diagnostic Laparoscopy Clinical Guidelines p. 1-e16.

13.E Myers, DO Kavanagh, H Ghous, D Evoy, EW McDermott (2010) The impact of evolving management strategies on negative appendicectomy rate. Colorectal Dis 12(8): 817-e821.

14. MD Chandra Segaram, L Rothwell, EI An, R Miller (2012) Pathologies of the appendix: a 10-year review of 4670 appendicectomy specimens. ANZ J Surg 82(11): 844-e847.

15. GE Jones, S Kreckler, A Shah, MJ Stechman, A Hand (2012) Increased use of laparoscopy in acute right iliac fossa pain - is it good for patients? Colorectal Dis 14(2): 237-e242.

16. SS Jaunoo, L Hale, JPM Masters, SR Jaunoo (2012) An international survey of opinion regarding investigation of possible appendicitis and laparoscopic management of a macroscopically normal appendix, Ann R Coll Surg Engl 94(7): 476-e480.

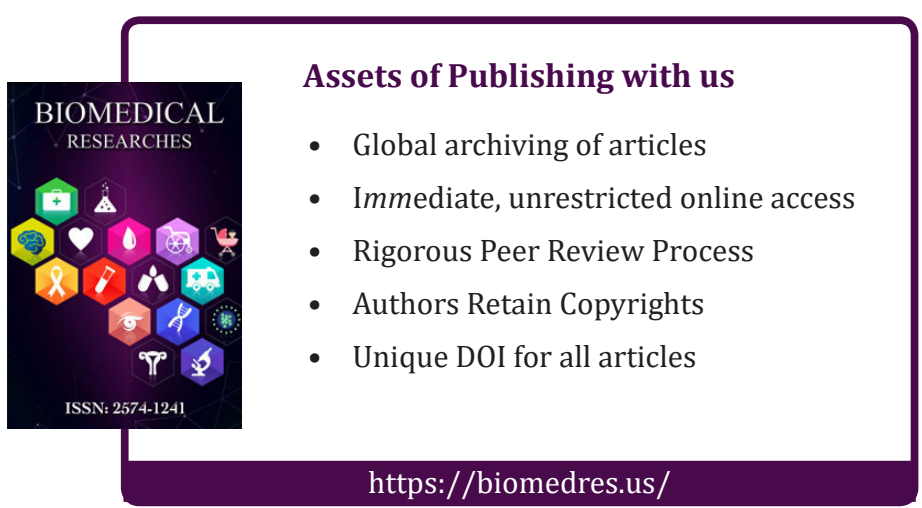

